\title{
Evaluation and remediation of bulk soap dispensers for biofilm
}

\author{
Authors: Lindsey A. Lorenz, Bradley D. Ramsay, \\ Darla M. Goeres, Matthew W. Fields, Carrie A. \\ Zapka, \& David R. Macinga
}

NOTICE: This is an Accepted Manuscript of an article published in Biofouling on January 2012, available online: http://www.tandfonline.com/10.1080/08927014.2011.653637.

Lorenz LA, Ramsay BD, Goeres DM, Fields MW, Zapka CA, Macinga DR, "Evaluation and remediation of bulk soap dispensers for biofilm," Biofouling: The Journal of Bioadhesion and Biofilm Research, January 2012 28(1):99-109 


\title{
Evaluation and remediation of bulk soap dispensers for biofilm
}

\author{
Lindsey A. Lorenz ${ }^{\mathrm{a}}$, Bradley D. Ramsay ${ }_{b}^{\mathrm{a}}$, Darla M. Goeres ${ }^{\mathrm{a}}$, Matthew W. Fields ${ }^{\mathrm{a}}$, \\ Carrie A. Zapka ${ }^{b}$ and David R. Macinga \\ ${ }^{\text {a }}$ Center for Biofilm Engineering, Montana State University, Bozeman, Montana 59717, USA; b GOJO Industries, Inc., Akron, OH \\ 44311, USA
}

Recent studies evaluating bulk soap in public restroom soap dispensers have demonstrated up to $25 \%$ of open refillable bulk-soap dispensers were contaminated with $* 6 \log 10\left(\mathrm{CFU} \mathrm{ml}{ }^{71}\right)$ heterotrophic bacteria. In this study, plastic counter-mounted, plastic wall-mounted and stainless steel wall-mounted dispensers were analyzed for suspended and biofilm bacteria using total cell and viable plate counts. Independent of dispenser type or construction material, the bulk soap was contaminated with 4-7 $\log _{10}\left(\mathrm{CFU} \mathrm{ml}{ }^{71}\right)$ bacteria, while $4-6 \log _{10}\left(\mathrm{CFU} \mathrm{cm}{ }^{72}\right)$ biofilm bacteria were isolated from the inside surfaces of the dispensers (n $1 / 46$ ). Dispenser remediation studies, including a $10 \mathrm{~min}$ soak with $5000 \mathrm{mg}^{71}$ sodium hypochlorite, were then conducted to determine the efficacy of cleaning and disinfectant procedures against established biofilms. The testing showed that contamination of the bulk soap returned to pre-test levels within 7-14 days. These results demonstrate biofilm is present in contaminated bulk-soap dispensers and remediation studies to clean and sanitize the dispensers are temporary.

Keywords: biofilm; bulk soap; soap dispensers; efficacy testing

\section{Introduction}

Hand washing has long been recognized to play an important role in public health (Garner and Favero 1986), and is generally accepted as an important practice to help prevent the spread of infectious microorganisms, which is especially significant in the healthcare industry. Hand washing sinks and liquid soap are generally provided to patrons of public restrooms to encourage good hand hygiene. Shared public bathrooms, however, can be a vector, con-tributing to the spread of pathogenic microorganisms (Mokhtari and Jaykus 2009). As early as the 1960 s, studies were published regarding significant surface contamination of bar soap (Bannan and Judge 1965; Kabara and Brady 1983). Liquid soap was eventually recommended to be a more hygienic solution, and dispensers were developed to distribute liquid soaps (Graf et al. 1988; Chattman et al. 2011).

Like bar soaps, liquid soap dispensers have been associated with microbial contamination issues. Reports dating back to the 1960s have linked bulk liquid hand soap and hand lotion contamination to nosocomial infections in hospital operating rooms and neonatal units (Morse et al. 1967; Archibald et al. 1997; Sartor et al. 2000; Rabier et al. 2008; Buffet-Bataillon et al. 2009). Washing with contaminated soap can leave more bacteria present on the hands after the washing event than before, which undermines the effectiveness of hand washing (Sartor et al. 2000; Zapka et al. 2011). In 1986, the healthcare industry hand hygiene guidelines recognized that 'since liquid-soap containers can become contaminated and might serve as reservoirs of microorganisms, reusable liquid containers need to be cleaned when empty and refilled with fresh soap. Completely disposable containers obviate the need to empty and clean dispensers.' (Garner and Favero 1986). In response to this guideline, the use of bulk hand soap dispensers is now rare in US healthcare settings. How-ever, these types of dispensers are still common in public restrooms. Recent research has demonstrated that up to $25 \%$ of bulk hand soap dispensers from office buildings, health clubs, schools, food service centers, retail spaces and other locations are contaminated. Heterotrophic bacteria in contaminated soap averages $6 \log _{10}$ (CFU ml ${ }^{71}$ ), which is approximately 1000 times in excess of what industry guidelines recommend (Krowka and Bailey 2007; Chattman et al. 2011).

There are numerous unique dispenser designs but all include a reservoir area to store the soap, a mechanism to pump the soap out of the reservoir onto hands, and a way to refill the dispenser with new soap. Dispensers are constructed of metal or plastic and are typically semipermanently mounted to the wall or under the counter near the sink. Dispensers are 
designed to be refilled by one of two methods: bulk refill and sealed soap refill. Bulk refill dispensers are manually refilled by pouring soap through an opening in the top from a separate bulk soap refill bottle, commonly supplied in a 1 gallon volume. These bulk soap dispenser models typically have a built-in permanent nozzle through which soap is dispensed and is not replaced under normal circumstances. Sealed soap dispensing systems, in contrast, are typically refilled by inserting a new bag or cartridge of soap that contains a new built-in nozzle. As such, the nozzles in these systems are replaced regularly and the soap does not come into contact with the dispenser itself. Empty cartridges are then either disposed or recycled.

Personal care and cosmetic products, such as soap, are not expected to be sterile, but US manufacturers are required by law to ensure that their products do not present a hazard to consumers when they are used as directed (Steinberg 2006). The Federal Food, Drug, and Cosmetic Act 'requires that successful preservation can only be established if one considers all aspects of development from concept and design through manufacturing to the last consumer use before disposal' (Geis 2006). Industry guidelines suggest that to be safe, a product should not contain any pathogens and that the bacterial load should not exceed 1000 total bacteria per gram or milliliter of product (Krowka and Bailey 2007). In order to protect products from contamination during use, soap manufacturers include preservatives in their formulations and verify their performance by testing that each newly-developed formulation effectively inhibits the growth of a range of microorganisms (Sutton 2006). Liquid hand soaps, however, are perishable and can become contaminated with microorganisms under certain adverse circumstances, particularly when consumers use or store the product in unintended ways that are hostile to preservative efficacy (Geis 2006). Occasionally, products are sold that are either already contaminated (intrinsic contamination) or that are inherently susceptible to becoming contaminated because of poor formulation design. However, the primary cause of failure of even a robust, well-preserved formulation is the introduction of contamination during use of the product when a consumer intentionally adds water, mixes products, or stores the product in inhospitable conditions, such as in warm or humid places (extrinsic contamination) (Geis 2006). The design of packaging and dispensing mechanisms used to store and deliver products affects the probability that a product will become contaminated. Systems that have an open design and that allow for increased opportunity for consumers to manipulate the product inside are inherently at greater risk of becoming contaminated as compared to products with a closed design (Garner and Favero 1986; Brannan and Dille 1990; Geis 2006).
Dispenser design and construction of soap packaging is a critical factor to both the occurrence of contamination and the challenge of contamination remediation. The likelihood of extrinsic contamination is greatest when products are packaged, stored, or used in a manner that allows for repeated introduction of microorganisms from the consumer or the surrounding environment (Brannan and Dille 1990; Geis 2006). Dispenser designs, particularly those for wall-mounted dispensers, do not take into consideration the potential for microbial contamination, thus, cleaning is impractical because the dispensers are often securely bolted into walls, making them difficult to remove. For this reason, the same dispensers often remain in facilities for many years. Some wall-mounted dispensers are designed with a nozzle that is located centimeters above the bottom of the dispenser, rather than dispensing the soap from the bottom of the dispenser. This design flaw ensures that the dispenser will never completely drain. Once the soap becomes contaminated, this serves to provide a reservoir of bacteria that are uniquely adapted to survive in the soap environment. Also, some counter-mounted dispensers are sold with one dispensing pump to be reused between bottles (Sartor et al. 2000). Once the pump becomes contaminated, it can transfer the bacteria between bottles (Graf et al. 1988).

Remediation of contaminated dispensers is one option for reducing potential health risks to the general public. There are no published research studies to date that have determined if there is an effective way to eliminate or reduce the contamination problem by washing and/or sanitizing the dispenser. Furthermore, even as far back as the late 1980 s, biofilm was suspected of being present in bulk soap dispensers (Graf et al. 1988). Given that bacterial biofilm is known to be more tolerant to disinfectants (Stewart et al. 2000; Donlan and Costerton 2002; Smith and Hunter 2008; Peeters et al. 2008), biofilms likely survive on internal surfaces in contact with soap. While most published studies only tested the bulk soap coming out of the dispenser for bacterial contamination, the entire soap dispenser could be considered a microbial habitat and should be examined. This examination should include both the bulk soap for planktonic contamination and the inner dispenser surfaces to test for the presence of biofilm.

The objectives of this study were to test for the presence of biofilm within dispensers collected from public restrooms and to determine which organisms were present, to understand the efficacy of cleaning and disinfection procedures against established biofilm, and to examine the recurrence of bulk soap contamination following cleaning. Plastic counter-mounted, plastic wall-mounted, and stainless steel (SS) wall-mounted 
dispensers were analyzed for planktonic and biofilm heterotrophic and coliform bacteria using viable plate counts (VPC) and total cell counts (TCC). Isolated bacterial colonies were identified using biochemical and molecular profiling. Once the presence of biofilm within dispensers was confirmed, several washing and sanitizing procedures were evaluated for their ability to remediate contamination using both plastic and SS wall-mounted dispensers.

\section{Methods}

\section{Sampling dispensers for biofilm}

\section{Test dispenser information}

Three counter-mounted plastic dispensers from a shopping complex, two plastic wall-mounted dispensers from an elementary school, and two SS wall-mounted dispensers from a middle school and high school, all located in Ohio, USA were evaluated. The dispensers were sampled in the field and determined to be contaminated prior to being sent to the Center for Biofilm Engineering (CBE) for analysis. The plastic dispensers tested were designed with a top lid that completely lifted open for refilling the dispenser with new soap. The SS dispensers were designed with a small, hinged lid that is lifted to refill the dispenser with soap.

\section{Experimental design}

A schematic of the process used to sample the refillable soap dispensers for viable and total cells is found in Figure 1. Dispensers were visually inspected and imaged after arrival from the collection site. Three samples were collected from each dispenser: bulk soap to enumerate viable, planktonic bacteria $\left(\mathrm{CFU} \mathrm{ml}{ }^{-1}\right)$; rinse water to enumerate loosely-attached, surfaceassociated bacteria (CFU cm${ }^{-2}$ ); and inner surface scrapings to determine the density of attached, biofilm bacteria $\left(\mathrm{CFU} \mathrm{\textrm {cm } ^ { - 2 }}\right.$ ). In addition, TCC were determined for each sample type collected, as described below.

\section{Determination of planktonic bacteria}

For the plastic counter- and wall-mounted dispensers, the soap was drained through the nozzle into a sterile beaker containing $220 \mathrm{~g}$ of $3 \mathrm{~mm}$ glass beads. For the SS dispensers, the soap was drained into a sterile glass beaker, and after vigorous mixing, a $10 \mathrm{ml}$ aliquot was added to a $50 \mathrm{ml}$ conical vial containing $10 \mathrm{~g}$ of glass beads.

\section{Determination of loosely-attached bacteria}

After the soap was removed from the dispenser, $100 \mathrm{ml}$ of sterile phosphate buffered water was added to the dispenser and swirled around to remove any looselyattached bacteria. For the plastic dispensers, the rinse water was drained into a sterile beaker containing $60 \mathrm{~g}$ of glass beads. For the SS dispensers, the rinse water was drained into a beaker and a $10 \mathrm{ml}$ aliquot was collected for culturing.

\section{Determination of strongly-attached bacteria}

For the plastic dispensers, the entire inside of the dispenser was scraped with a Teflon scraper and then rinsed with $100 \mathrm{ml}$ of DeyEngley (D/E) Neutralizing Broth.

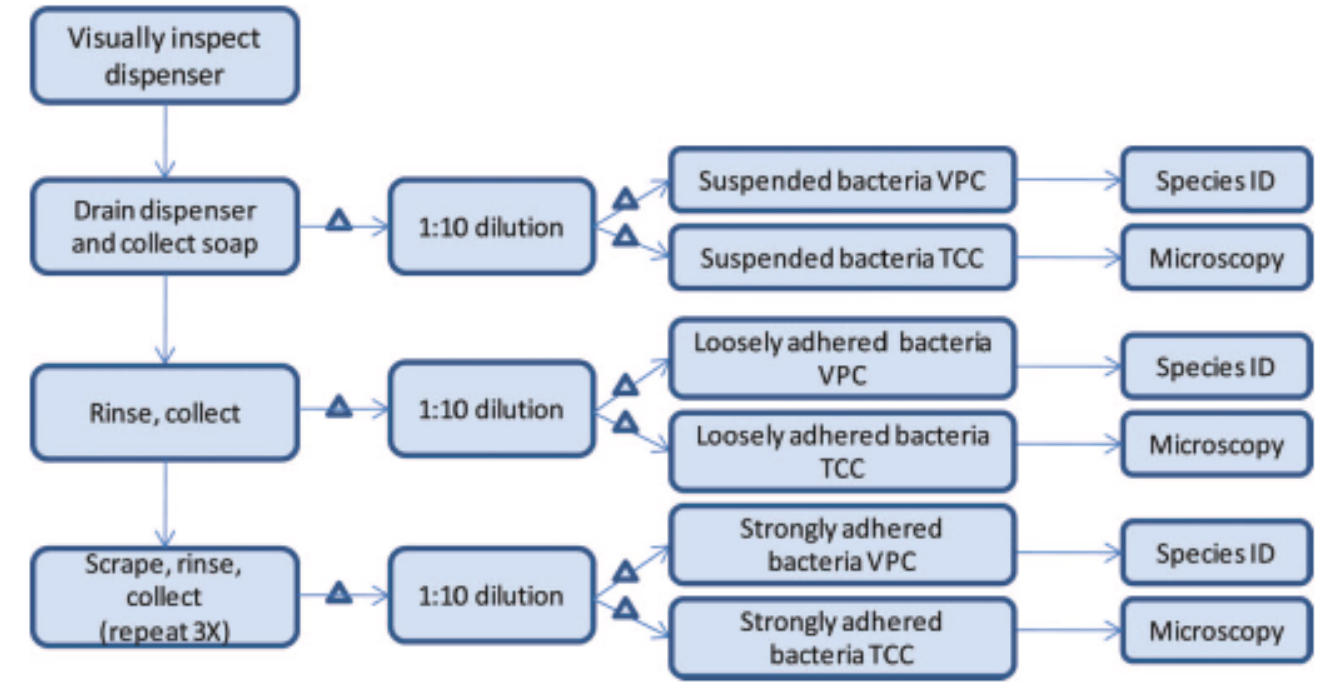

Figure 1. Schematic of the experimental design used to analyze bacteria suspended in the soap and loosely-or strongly-attached to the inside surfaces of contaminated bulk soap dispensers. Three samples were collected and analyzed for viable cells (VPC) and total cells (TCC). $\Delta=$ sample disaggregation steps. 
The $\mathrm{D} / \mathrm{E}$ broth was poured into a beaker containing 185 $\mathrm{g}$ of glass beads. The scrape and rinse procedure was completed three times and all rinses were combined.

For the SS dispensers, $150 \mathrm{ml}$ of cold phosphate buffered water were added to the dispenser. The dispenser was shaken vigorously for $5 \mathrm{~min}$ and the inside surfaces of the dispenser that were accessible were scraped with a sterile Teflon scraper.

\section{Disaggregation and plating methods}

All samples were neutralized with $\mathrm{D} / \mathrm{E}$ broth. Three cycles of sonication and vortexing (1 min each) followed to disaggregate the biofilm. Sterile glass beads were included to aid in biofilm disaggregation. The efficiency of this method was confirmed microscopically. Samples were serially diluted and $1 \mathrm{ml}$ aliquots were plated on both R2A and MacConkey agar. The R2A plates were incubated at room temperature for 7 days and the MacConkey plates were incubated at $36^{\circ} \mathrm{C}$ for a period of $24-72 \mathrm{~h}$. In addition, $1 \mathrm{ml}$ of the disaggregated, undiluted soap was plated.

For TCC, an additional $1 \mathrm{ml}$ aliquot from the diluted sample was pipetted onto a $0.2 \mu \mathrm{m}$ membrane. LIVE/DEAD BacLight Bacterial Viability Kit stain (Invitrogen \#L7012, Carlsbad, CA) was added, incubated for $15 \mathrm{~min}$ in the dark, and after rinsing, the membrane was placed on a glass slide. The total cell count slides were imaged on a Nikon Eclipse E800 microscope with a FITC cube (ex 480/15, DM 505, em $535 / 20$ ) for the green and a TRITC cube (ex 546/5, DM 575 , em 590 LP) for the red. Images were analyzed for total cells regardless of the color the cell stained. A scan of 20 fields per slide was performed and this information was processed for total counts per sample dilution using Metamorph, v7.6.4 Software (MDS Analytical Technologies, Sunnyvale, CA).

\section{Identification of bacterial isolates}

Colonies collected from the three sample types that expressed a unique morphology were streaked for isolation and sent to an outside laboratory (Medical Laboratory Services, Inc., Bozeman, MT) for bacterial identification based upon biochemical profiling. Identification of bacterial isolates was confirmed by sequence determination of the $\mathrm{V} 1-\mathrm{V} 3$ region of the SSU rRNA gene. The SSU rRNA gene was amplified with previously described primers FD1 and 1540R and sequenced with $529 \mathrm{R}$ via capillary Sanger sequencing (Ye et al. 2004; Hwang et al. 2009). Sequences were identified using the BLASTn algorithm through NCBI (http://ncbi.nlm.nih.gov/blast).

For the plastic wall-mounted dispensers, the field identifications (from historical data) and laboratory identifications were determined using biochemical profiling and molecular analysis. For the SS wallmounted dispensers, the laboratory identifications were determined biochemically and the isolated colonies used in the biochemical identifications were sent in for molecular testing to provide direct comparisons between the two methods.

\section{Molecular analysis of whole biofilm community}

Using separate dispensers from above, two plastic wallmounted and two SS wall-mounted dispensers were sampled to determine microbial diversity of biofilm within the dispensers. For each dispenser tested, bulk soap was removed and $100 \mathrm{ml}$ cold, sterile $1 \mathrm{X}$ PBS were added. The inside surfaces of the dispenser were scraped into the PBS and transferred to $50 \mathrm{ml}$ conical centrifuge tubes. Biomass was collected via centrifugation and multiple pellets from the same dispenser were combined until all biomass was in a single pellet for each sample. Pellets were resuspended in $10 \mathrm{ml}$ of PowerBead solution and transferred into sterile mortars with sand. Samples were flash frozen with liquid nitrogen and ground with pestles three times. The whole sample was collected into PowerBead tubes and nucleic acid extraction was done according to the manufacturer's instructions with the PowerMax Soil DNA Extraction Kit (MO BIO, Inc., Carlsbad, CA). The extracted DNA was amplified as above with primers FD1 and 1540R using PCR program $80^{\circ} \mathrm{C} 1: 30,94^{\circ} \mathrm{C} 2: 00,25$ cycles of $\left(94^{\circ} \mathrm{C} 0: 30,58^{\circ} \mathrm{C} 1: 00\right.$, $72^{\circ} \mathrm{C} 1: 00$ ), $72^{\circ} \mathrm{C} 7: 00$ followed by $4^{\circ} \mathrm{C}$ hold. Appropriately-sized DNA was cloned into plasmid pCR2.1TOPO (plastic) or pCR4-TOPO (SS), transformed into competent E.coli $\mathrm{DH} 5 \alpha$ and plated on LB-Kan 50 plates as per the manufacturer's instructions (Invitrogen, Inc., Carlsbad, CA). Transformants were screened for appropriately-sized inserts using primers M13F and M13R. Ninety-six M13 amplicons were submitted from each dispenser for Sanger sequencing using primer $529 \mathrm{R}$. Sequence libraries were checked for chimeras and identified as described above.

\section{Dispenser imaging}

Prior to any sampling steps, the dispensers were visually inspected and various outside and/or removable dispenser pieces were imaged using a Nikon SMZ1500 stereo zoom microscope.

\section{Experimental design of remediation study}

Washing studies were conducted on plastic and SS wall-mounted dispensers. Five plastic wall-mounted dispensers from an elementary school in Ohio were used in the first set of experiments. Some of these 
dispensers were previously used to investigate hand transfer of contaminants in a different study (Zapka et al. 2011). Eight SS wall-mounted dispensers from a school district in New Jersey were used in the second set of experiments. Each experiment included a positive control (randomly chosen dispenser that had tested positive for contamination in the bulk soap) and a negative control (a new dispenser that had never tested positive for bacteria in the bulk soap). The experiments were performed in triplicate and control dispensers remained the same for each of three experimental repeats. The remaining dispensers used in the studies had all tested positive for viable bacteria (at least $3 \log _{10}\left(\mathrm{CFU} \mathrm{ml} \mathrm{m}^{-1}\right)$ ) in the bulk soap prior to commencing each washing experiment. The washing procedure tested on each dispenser was randomly assigned before every experiment.

The washing procedures were designed to vary in difficulty and to utilize products that would be readily available to any cleaning personnel, including the use of tap water. Just prior to washing the dispenser, a sample of the bulk soap was collected and analyzed for heterotrophic bacteria. Samples from plastic dispensers were neutralized with $\mathrm{D} / \mathrm{E}$ Neutralizing Broth and disaggregated and plated on R2A, while samples from SS dispensers were neutralized with a modified Butterfield's phosphate buffer solution containing lecithin, polysorbate $80, \mathrm{KH}_{2} \mathrm{PO}_{4}, \mathrm{~K}_{2} \mathrm{HPO}_{4}, \mathrm{Na}_{2} \mathrm{~S}_{2} \mathrm{O}_{3} \cdot 5 \mathrm{H}_{2} \mathrm{O}$, Tamol SN, and Triton $\mathrm{X}-100 \quad\left(\mathrm{BPB}^{+}\right.$Neutralizer) (Beausoleil 1999), followed by disaggregation and plating on TSA. The control dispensers were then drained and refilled with an antibacterial soap labeled to contain triclosan (percent triclosan not listed on the label) for the plastic dispensers or a bland (nonantimicrobial) soap for the SS dispensers. The soap formulation used to fill each dispenser was consistent with the formulation used to fill that dispenser in the field. The test dispensers were washed with sodium hypochlorite $\left(5000 \mathrm{mg} \mathrm{l}^{-1}\right)$, a quaternary ammonium compound-containing disinfectant (Ecolab Oasis 146 Multi-Quat Sanitizer, $8 \mathrm{ml} \mathrm{l}^{-1}$ ), or a mildew remover (Tilex Mildew Root Penetrator \& Remover, $24,000 \mathrm{mg}$ $1^{-1}$ sodium hypochlorite, active ingredient), as depicted in Figure 2. They were then filled with the appropriate soaps as described above. The bulk soap from all the dispensers was then sampled immediately after filling and for up to 2 weeks or until the population reached pre-test levels. Both the fresh soap and tap water were plated and tested on each experiment day for viable cells.

\section{Results}

\section{Planktonic and biofilm contamination}

Bulk soap from contaminated dispensers harbored between 3.7 to $6.7 \log _{10}\left(\mathrm{CFU} \mathrm{ml}{ }^{-1}\right)$ of viable coliform and heterotrophic bacteria and between 6.9 to 8.0 $\log _{10}\left(\mathrm{CFU} \mathrm{ml} \mathrm{m}^{-1}\right.$ ) total cells (Figure 3). Soap from plastic wall-mount dispensers had the highest density of viable planktonic bacteria (5.4 to $6.7 \log _{10}$ (CFU $\mathrm{ml}^{-1}$ )) while plastic counter-mounted dispensers contained the lowest density ( 3.7 to $4.9 \log _{10}\left(\mathrm{CFU} \mathrm{ml}{ }^{-1}\right.$ )) and SS wall-mounted dispensers contained an intermediate density ( 4.9 to $5.2 \log _{10}\left(\mathrm{CFU} \mathrm{ml} \mathrm{ml}^{-1}\right)$ ). The TCC in the soap were $\sim 1$ to 3 logs greater than the viable counts for all of the dispensers.

Loosely- and strongly-adhered viable coliform or heterotrophic cells were present at densities between 3.3 to $6.4 \log _{10}\left(\mathrm{CFU} \mathrm{cm}{ }^{-2}\right)$ in all dispensers (Figure 4). The SS wall-mounted dispensers had the highest density of surface-associated viable bacteria (5.1 to $6.4 \log _{10}\left(\mathrm{CFU} \mathrm{cm} \mathrm{cm}^{-2}\right)$ ) as compared to the plastic counter-mounted and wall-mounted (3.3-5.8 $\log _{10}(\mathrm{C}$ $\mathrm{FU} \mathrm{cm}{ }^{-2}$ )) dispensers. The TCC from the loosely- and strongly adhered bacteria were generally greater than the loosely- and strongly-adhered viable bacteria, except for the strongly-adhered bacteria from the plastic wall-mounted dispenser. For the majority of dispensers, slightly more strongly-adhered and total cell count bacteria were recovered than looselyadhered bacteria, except for the plastic countermounted dispensers, in which much higher densities of loosely-attached bacteria and TCC were recovered (6.3 to 6.9 as compared to the strongly-associated bacteria at 4.6 to 5.1 ).

\section{Bacterial identification}

The colonies recovered from the plastic countermounted dispensers were identified through biochemical profiles as Klebsiella oxytoca and Kluyvera ascorbata, both of which are Gram-negative opportunistic pathogens. The bacteria identified in the plastic wall-mounted dispensers were commonly Gram-negative, presumptive opportunistic pathogens (eg Providencia, Citrobacter, Klebsiella, Serratia, and Pseudomonas) (Table 1). Bacterial populations were also identified via clone libraries of SSU rRNA gene sequences. The isolates identified with both biochemical and molecular techniques revealed similar identifications at the genus level, although not surprisingly the clone library data identified potential organisms that were not cultivated. The bacteria identified in the SS wall-mounted dispensers were consistent with that observed for the other dispensers (Table 2). In total, the SS dispensers contained bacteria from five unique genera that included Pseudomonas, Providencia, Serratia, Stenotrophomonas and Acinetobacter. Interestingly, the molecular data did not reveal additional sequences that were not cultivated from the SS dispensers. In previous unpublished work, historical data indicated 


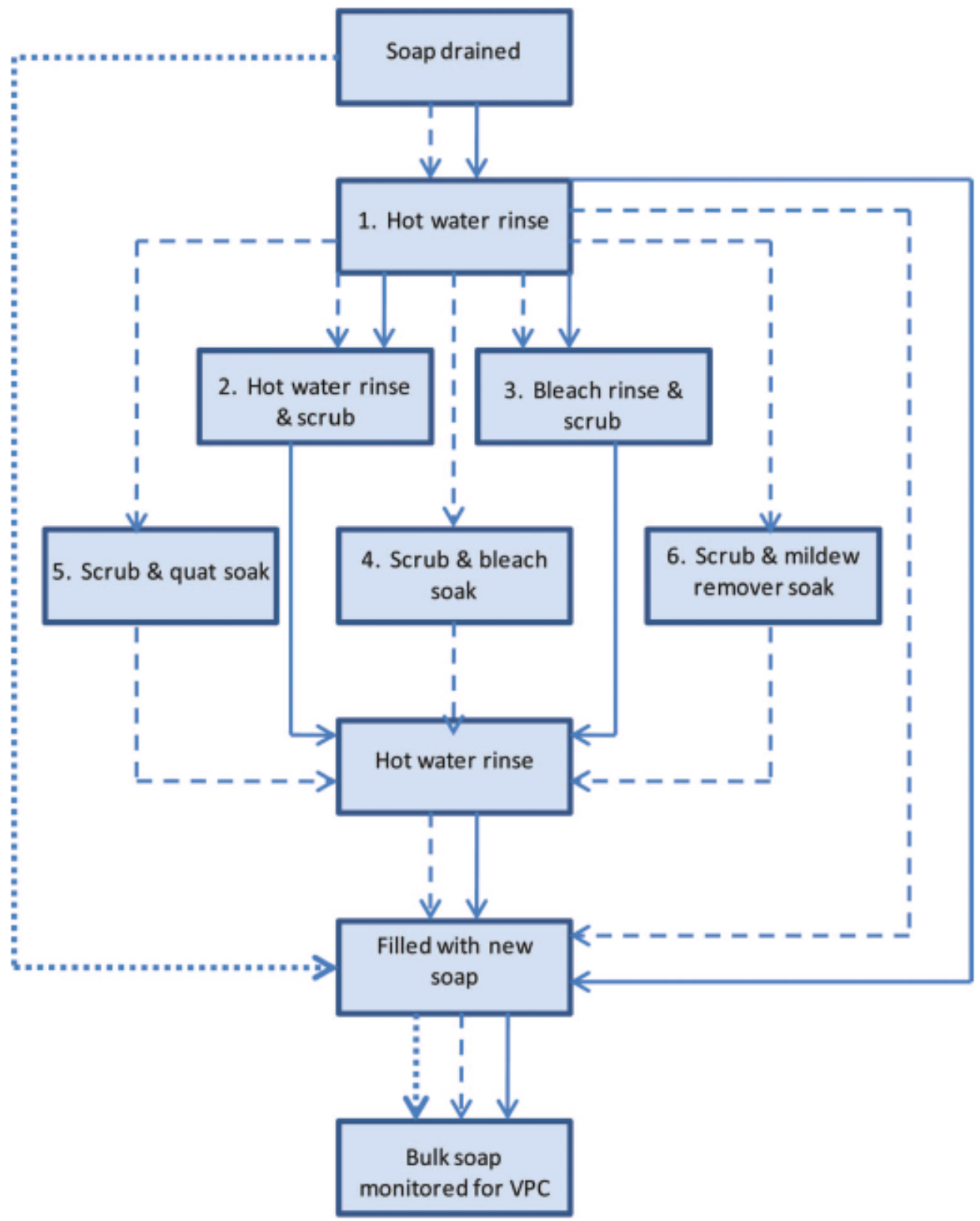

Figure 2. Schematic of the experimental design used to evaluate the effectiveness of dispenser remediation procedures. Procedures 1, 2, and 3 were followed for plastic wall-mounted dispensers (solid lines). Procedures 1-6 were tested for the SS dispensers (dashed lines). The dotted line denotes the control dispenser protocol.

that the dominant colony types in each dispenser were Pseudomonas aeruginosa and Serratia liquefaciens. This research confirmed that these genera were present in the respective dispensers but did not confirm that they were the dominant colony types. Bacterial isolates obtained from SS dispensers were also identified using both SSU rRNA gene sequencing biochemical profiling to compare the two techniques. The results from the comparison revealed equivalent identities at the genus level for all but one of 14 isolates.

\section{Effectiveness of dispenser remediation techniques}

The heterotrophic plate count results of the dispenser washing experiments are shown in Figures 5 and 6 for the plastic wall-mounted and SS wall-mounted dispensers, respectively. In Figure 5, the standard error of the mean (SEM) for the hot water rinse procedure was 0.10 and 0.47 on day 0 and day 4 , as averaged over the three experiments. The SEM for the hot water rinse and scrub procedure on day 0 was 0.28 and ranged from 0.07 to 0.53 on days 0,4 , and 7 for the scrub and 


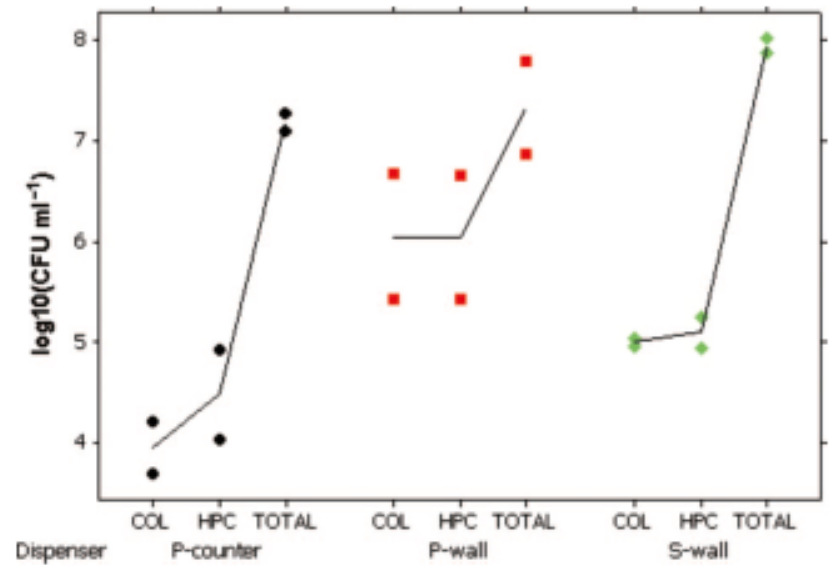

Figure 3. Coliform (COL), heterotrophic (HPC), and total cell count (TOTAL) results from the bulk soap for plastic counter-mount, plastic wall-mount, and SS wall-mount dispensers ( $n=2$ of each). The black solid line connects the mean $\log _{10}\left(\mathrm{CFU} \mathrm{ml} \mathrm{m}^{-1}\right)$ of the data points.

sodium hypochlorite rinse washing procedure, over the three experiments. The triplicate experiments for these dispensers were not conducted consistently with respect to the frequency of plating. In experiment 1 , the dispensers were only plated on day 0 and 14 , whereas in experiment 2, they were plated on days 0,2 , 4,7 , and 10 . The dispensers were plated on days $0,1,4$, and 7 for experiment 3 and for all experiments, plating was discontinued once the bacterial counts returned to pre-test contamination levels. For these reasons, the SEM could not be calculated for all dispensers and all experiments for each day.

In Figure 6, the SEM for the hot water rinse procedure over the three experiments was $0.30,0.14$, and 0.20 for days 0,2 , and 4 . The SEM could not be calculated for day 7 because some of the dispensers had reached their pre-test contamination levels and plating was discontinued. The SEM for the hot water rinse and scrub procedure was $0.27,0.25,0.15$, and 0.15 for days $0,2,4$, and 7 averaged over three experiment replicates. For the scrub and sodium hypochlorite rinse procedure, the SEM was 0.25 , $0.52,1.01$, and 0.34 for days $0,2,4$, and 7 . The SEM could not be calculated on day 10 because some of the dispensers had already reached their pre-test contamination levels. For the $10 \mathrm{~min}$ sodium hypochlorite soak procedure and for the $10 \mathrm{~min}$ quat soak procedure, the SEM was $0.26,0.31,0.71$, and 0.22 , and $0.28,0.15,0.87$, and 0.16 on days $0,2,4$, and 7 , respectively. For the $10 \mathrm{~min}$ mildew remover soak washing procedure, the SEM was $0.34,0.63,1.55$, and 1.24 for days $0,2,4$, and 7 . The SEM could not be calculated for days 10 and 14 because some of the dispensers had already reached their pre-test contamination levels and plating was discontinued.
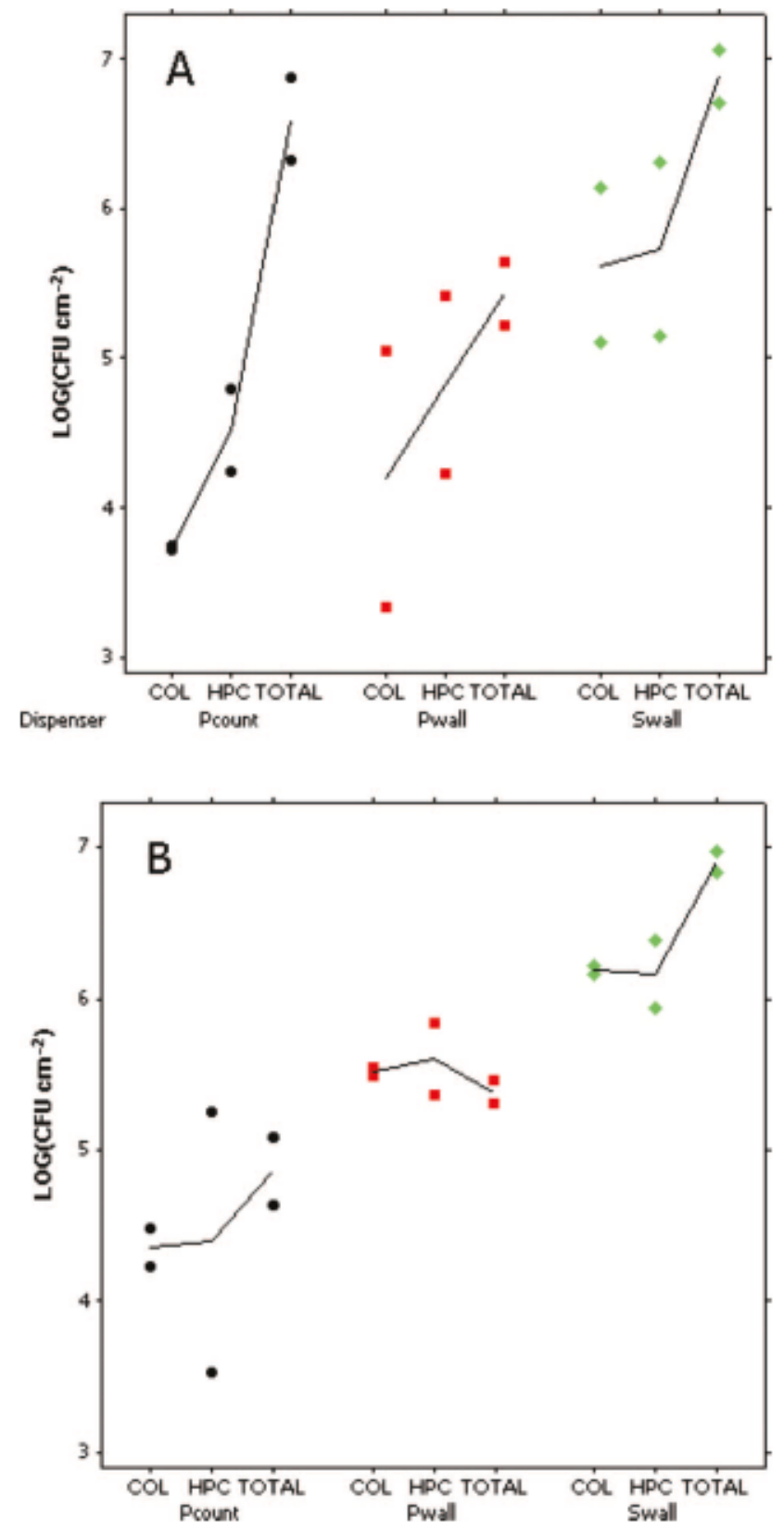

Figure 4. Coliform (COL), heterotrophic (HPC), and total cell count (TOTAL) results from the loosely-attached (Panel A) and strongly-adhered (Panel B) sampling steps for plastic counter-mounted, plastic wall-mounted, and SS wallmounted dispensers ( $n=2$ of each). The black solid line connects the mean $\log _{10}\left(\mathrm{CFU} \mathrm{cm} \mathrm{cm}^{-2}\right)$ of the data points.

The dispensers initially contained 4.3 to 6.0 $\log _{10}\left(\mathrm{CFU} \mathrm{ml} \mathrm{ml}^{-1}\right)$ in the bulk soap dispensed after cleaning. Rinsing the dispenser with hot water, with or without scrubbing, did little to reduce the contamination levels in the soap. Based upon industry guidelines that suggest a microbial load limit of $1000 \mathrm{CFU} \mathrm{ml}{ }^{-1}$, these soaps would be considered contaminated within $1-2$ days after performing the remediation procedures. 
Table 1. Bacteria identified in wall-mounted plastic dispensers.

\begin{tabular}{|c|c|c|c|}
\hline Organisms identified & $\begin{array}{c}\text { Field } \\
\text { identified }\end{array}$ & $\begin{array}{c}\text { Lab } \\
\text { identified }\end{array}$ & $\begin{array}{c}\text { Clone } \\
\text { library } \\
\text { analysis }\end{array}$ \\
\hline $\begin{array}{c}\text { Providencia rettgeri } \\
\text { Pseudomonas sp. }\end{array}$ & + & + & + \\
\hline$P$. aeruginosa & + & + & + \\
\hline P. fluorescens & + & & \\
\hline P. luteola & + & & \\
\hline P. stuzeri & + & & \\
\hline Citrobacter sp. & & & + \\
\hline C. koseri & + & & \\
\hline C. freundii & & + & \\
\hline Serratia sp. & & & \\
\hline S. oderifera & + & & \\
\hline S. liquefaciens & & + & \\
\hline S. rubidae & + & & + \\
\hline Stenotrophomonas sp. & & & + \\
\hline S. maltophilia & + & & \\
\hline Klebsiella pneumoniae & & + & \\
\hline Aeromonas hydrophilia & + & & \\
\hline Burkholderia cepacia & & + & \\
\hline Enterobacter sp. & & & + \\
\hline E. cloacae & & + & \\
\hline Achromobacter xylosoxidans & & & + \\
\hline Alcaligenes xylosoxidans & & & + \\
\hline Curvibacter sp. & & & + \\
\hline Leptothrix sp. & & & + \\
\hline Pelomonas sp. & & & + \\
\hline Delftia acidovorans & & & + \\
\hline Rubribacter xylanophilus & & & + \\
\hline
\end{tabular}

Table 2. Bacteria identified in SS wall-mounted dispensers.

\begin{tabular}{|c|c|c|c|}
\hline Organisms identified & $\begin{array}{l}16 \mathrm{~S} \text { ID } \\
\text { of isolates }\end{array}$ & $\begin{array}{c}\text { Biochemical } \\
\text { ID of } \\
\text { isolates }\end{array}$ & $\begin{array}{c}\text { Clone } \\
\text { library } \\
\text { analysis }\end{array}$ \\
\hline Pseudomonas sp. & & & + \\
\hline $\begin{array}{l}P . \text { aeruginosa } \\
P . \text { fluorescens/putida }\end{array}$ & + & $\begin{array}{l}+ \\
+\end{array}$ & \\
\hline Providencia sp. & + & & + \\
\hline P. vericola & + & & \\
\hline P. rettgeri & + & + & \\
\hline Serratia sp. & + & & + \\
\hline S. marcescens & & + & \\
\hline S. liquefaciens & & + & \\
\hline $\begin{array}{l}\text { Stenotrophomonas sp. } \\
\text { S. maltophilia }\end{array}$ & + & + & + \\
\hline Acinetobacter lwoffii & & + & \\
\hline $\begin{array}{l}\text { Alcaligenes/ } \\
\text { Achromobacter sp. }\end{array}$ & & & + \\
\hline
\end{tabular}

The most effective remediation treatments were the sodium hypochlorite soak, sodium hypochlorite rinse and scrub, and the mildew remover soak, which were all able to reduce the bacterial contamination densities to below the $1000 \mathrm{CFU} \mathrm{ml} \mathrm{m}^{-1}$ threshold for $\sim 4$ to 5 days after treatment. However, the levels in the soap continued to increase and returned to pre-remediation

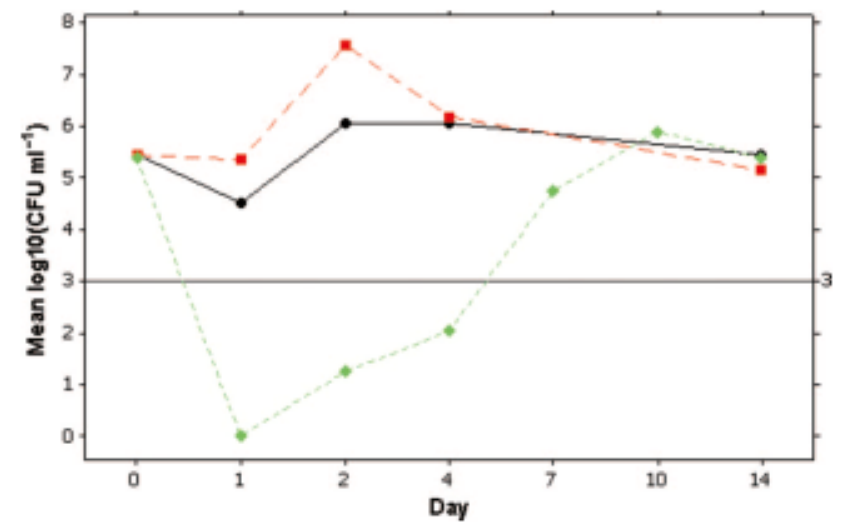

Figure 5. HPC results for plastic wall-mounted dispenser washing studies, averaged over three experiments. $\bullet=$ hot water rinse procedure; $\boldsymbol{\|}=$ hot water rinse and scrub procedure; $\downarrow$ scrub and sodium hypochlorite rinse washing procedure. The solid horizontal line at 3 $\log _{10}\left(\mathrm{CFU} \mathrm{ml} \mathrm{ml}^{-1}\right)$ depicts the cosmetic industry guideline recommendation.

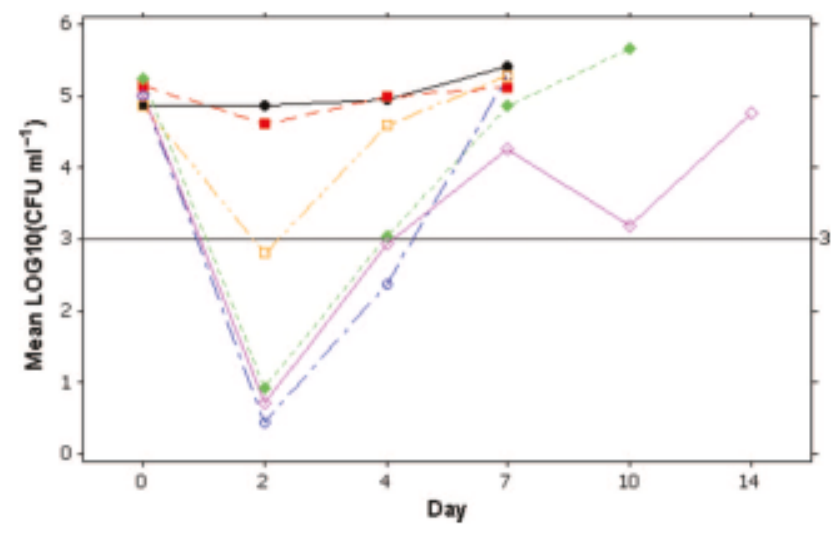

Figure 6. HPC results for SS wall-mounted dispenser washing studies, averaged over three experiments. $\bullet=$ hot water rinse procedure; $\mathbf{m}=$ hot water rinse and scrub procedure; $\bullet=$ scrub and sodium hypochlorite rinse washing procedure, $\circ=10 \mathrm{~min}$ sodium hypochlorite soak procedure; $\square=10 \mathrm{~min}$ quat soak procedure; $\diamond=10 \mathrm{~min}$ mildew remover soak washing procedure. The dispenser bulk soap was sampled until the populations reached pre-test contamination levels. The solid horizontal line at 3 $\log _{10}\left(\mathrm{CFU} \mathrm{ml} \mathrm{ml}^{-1}\right)$ depicts the cosmetic industry guideline recommendation.

levels after only 7 to 14 days post-remediation. The quat soak did little to decrease contamination levels, and on average, only decreased levels below the 3 $\log _{10}\left(\mathrm{CFU} \mathrm{ml}{ }^{-1}\right)$ microbial load limit for 2 days, posttreatment.

When considering the individual data points, the $10 \mathrm{~min}$ mildew remover soap procedure in experiment 3 took 10 days to recover beyond a $3 \log _{10}\left(\mathrm{CFU} \mathrm{ml}{ }^{-1}\right)$ level. Interestingly, it had reached that level after 4 days in the first two experiments. 
The effectiveness of the three remediation methods performed on both the plastic and SS dispensers (hot water rinse, hot water rinse and scrub, and sodium hypochlorite rinse and scrub) was not significantly different depending on dispenser type. Positive control dispensers, which were simply drained of soap and refilled with fresh soap, maintained their contamination levels at approximately $5 \log _{10}\left(\mathrm{CFU} \mathrm{ml} \mathrm{ml}^{-1}\right)$, and no bacteria were detected from the negative control dispensers throughout the experiments (data not shown).

\section{Discussion}

The results of this study demonstrate that open, bulkrefillable soap dispensers found to contain contaminated soap also contained bacterial biofilms. Three samples were collected from each dispenser to assess the bacterial contamination, viz. bulk soap, looselyattached cells, and biofilm. Analyzing the soap for bacteria in addition to the surface samples allowed for comparisons between historical findings, field data, and the present laboratory evaluation.

The density of surface-associated bacteria in SS wallmounted dispensers was up to ten-fold greater than that seen for the other two dispenser types. This is interesting because the bacterial density in the soap was slightly greater than that recovered in the plastic countermounted dispensers and slightly less than the bacteria recovered from the soap in the plastic wall-mounted dispensers. This result suggests that there is no direct correlation between biofilm density in a dispenser and the level of contamination in the bulk soap.

Previous reports suggest that bulk liquid samples are not necessarily predictive of the microbial health of the system (Goeres 2010). In general, if the bulk soap is contaminated, then biofilm is also most likely present in the dispenser. Perhaps the most interesting case would be to determine whether dispensers containing no bulk soap contamination still contain biofilm. Additional factors that would be interesting to include in a correlation study are the type of soap, the location of dispenser, and the use pattern.

For this study, the type of dispenser (plastic wallmounted, plastic counter-mounted and SS wallmounted) did not appear to be a significant factor, although a slightly greater diversity of organisms was detected in the plastic dispensers. This is an interesting result given the design of the SS dispensers, which does not allow for the dispenser to ever completely empty.

Bacterial isolates from the soap were almost exclusively Gram-negative. While isolates were identified to at least the genus level, the identifications provided a qualitative description of organisms contaminating the dispensers but did not serve to quantify each species. In most cases, molecular typing of the isolates provided similar results to the biochemical typing. Identifications from both methods are limited to matching the biochemical profile or the sequence to an organism already in the database. Biochemical profiling of environmental isolates is particularly limited due to the extremely great diversity of organisms which have not yet been characterized as well as those multiple species which are similar, if not identical, in the limited size of the array used for profiling. While the bacterial diversity was relatively low compared to other environments, $16 \mathrm{~S}$ rRNA gene sequencing demonstrated the presence of organisms not detected via cultivation-based techniques in plastic dispensers. The same was not true for the SS dispensers. Identified isolates are consistent with organisms previously reported to have been isolated from liquid soap (Chattman et al. 2011; Zapka et al. 2011). The molecular data can be used to further direct cultivation methods in order to isolate a broader diversity of the present microbiota, which could be useful information when crafting new formulations of soap. Intentional incubation of isolates already known to be well-suited for survival in soaps during the formulation phase would give insight into the ability of the new formulation to resist bacterial growth. Future work could include molecular techniques that differentiate bacterial populations in the bulk soap $v s$ biofilm populations.

Inclusion of microscopy in these experiments proved to be useful for two reasons. First, the TCC demonstrated that only a fraction of the bacteria were recovered by the VPC. On average, the TCC were 1 to 2 $\log _{10}\left(\mathrm{CFU} \mathrm{ml}{ }^{-1}\right)$ higher than the VPC, indicating the presence of a population that was either non-viable or non-culturable by the plating techniques used in this study. Second, microscopy demonstrated whether or not the disaggregation method was adequate (Figure 7).

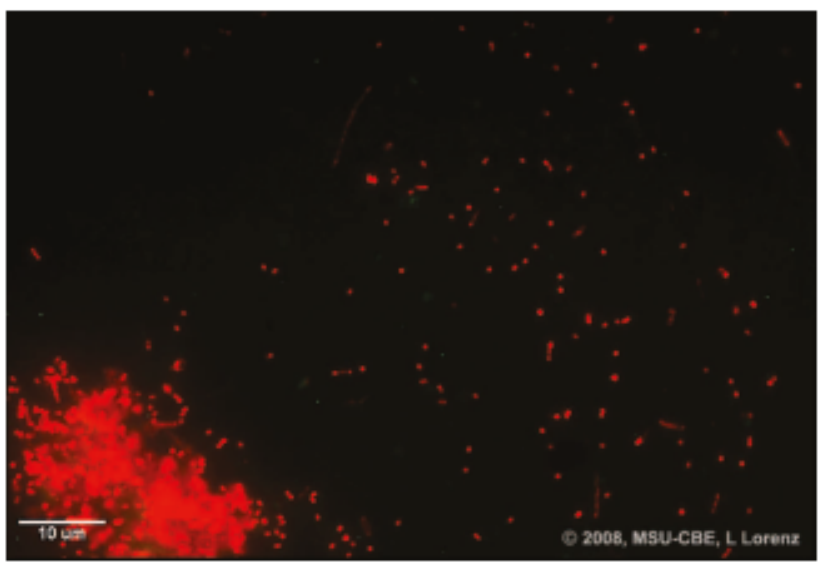

Figure 7. Total cell count image displaying biofilm clumping when disaggregation was inadequate. X100. Bar $=10 \mathrm{um}$. 
The physical properties of soap makes it challenging to disaggregate cell clusters; it foams when homogenized and is difficult to vortex vigorously, so microscopy was an important means by which to assess the disaggregation method used. Improper disaggregation will result in an underestimate of the viable cells present in a sample (Hamilton et al. 2009). Previously published results obtained without using disaggregation techniques showed that contaminated bulk soap in public restrooms contains an average of $6 \log _{10}\left(\mathrm{CFU} \mathrm{ml}{ }^{-1}\right)$ of heterotrophic bacteria, therefore, they may have underestimated the true levels of viable bacteria in the soaps (Chattman et al. 2011). Another interesting use of the imaging from the dispensers was to visually record that the dispensers often contained substances that presumably did not originate from the soap (Figure 8).

Once a biofilm has established on a surface, cleaning and eradicating the biofilm from that surface becomes a challenge, as the dispenser remediation experiments demonstrated. The ineffectiveness of washing soap bottles dates back to the 1960 s, so these findings are not surprising (Burdon and Whitby 1967). The present study showed that even soaking the dispensers with sodium hypochlorite, a quat, or with a full strength mildew remover for $10 \mathrm{~min}$ before adding new soap, was ineffective at eradicating biofilm. Because the soap used to refill each dispenser contained no detectable bacteria, the results demonstrated that the recovery of bacterial populations in the bulk soap resulted from dispersal of bacteria from biofilms present inside the dispensers. The rate of recolonization was inconsistent between replicates and likely represents a host of different factors including density of the biofilm, age of the biofilm, species composition of the biofilm, and quality of disruption of the biofilm during disinfection. The slowest recovery

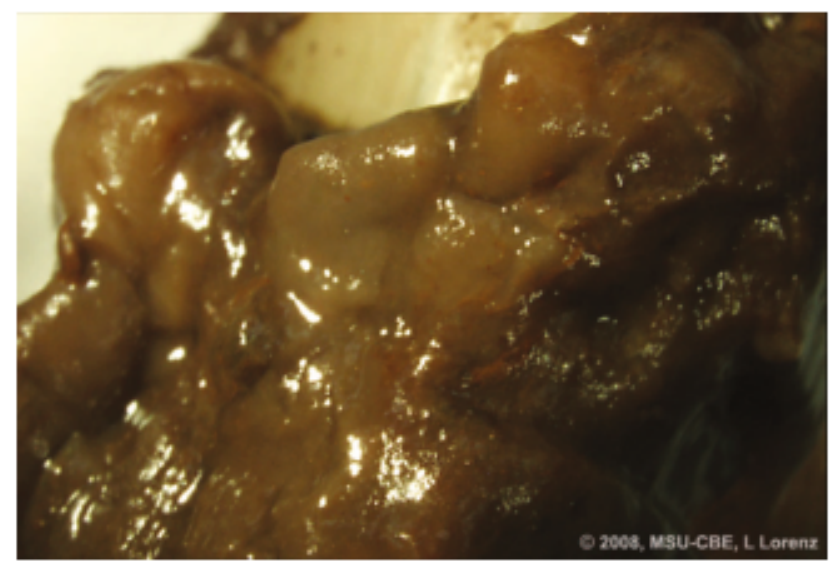

Figure 8. Stereoscope image of inner dispensing tube of a plastic counter-mounted dispenser coated with unknown brown substance. $7.5 \mathrm{X}$. took 14 days to reach pre-test contamination levels. This particular dispenser received the mildew remover treatment in experiment 3 , where the recovery was 14 days, but this dispenser also received that treatment in experiment 1 and received the sodium hypochlorite rinse treatment in experiment 2 . The mildew remover contains $24,000 \mathrm{mg} \mathrm{l}^{-1}$ sodium hypochlorite. It is conceivable that the two mildew sodium hypochlorite treatments, coupled with an approximate $5,000 \mathrm{mg} \mathrm{l}^{-1}$ sodium hypochlorite rinse treatment, all occurring within just under 2 months, were able to decrease the biofilm counts and delay regrowth and contamination, but still failed to completely eradicate the biofilm.

The soap dispenser remediation procedures evaluated in this study were very time and labor intensive and would not realistically be utilized by a custodial staff, especially in a facility with multiple dispensers to maintain. Furthermore, the trials conducted in triplicate were completed in rather quick succession, sometimes with just a week between replicate experiments. A custodian would be very unlikely to add an everyother-week soap dispenser cleaning regimen to an already long list of cleaning duties. Finally, the design of the dispenser systems contributes to the challenges of keeping them clean. They are composed of intricate pieces that are difficult to reach with a scrubbing brush. For instance, some of the top openings are quite small, making it difficult to use a scrubbing brush or to get into them at all. Bulk soap dispensers are constructed of many materials including plastics, SS, and rubber (gaskets). SS and rubber are incompatible with high level concentrations of sodium hypochlorite, which makes continuous cleaning of these materials with such disinfectants impractical, as the dispenser components will begin to corrode or deteriorate.

It is possible that dispenser design guidelines could be written to facilitate easier cleaning and disinfecting protocols for bulk soap dispensers. The SS wallmounted dispensers, for example, had an inefficient valve placement on the front of the dispenser, about $2.5 \mathrm{~cm}$ above the bottom, leaving a constant reservoir of soap. Valve systems that are both easily replaceable and not economically prohibitive would eliminate the need to clean intricate and delicate valve components. It is important to consider both the potential for contamination and the ease of cleaning a system as design parameters for a dispenser. As with any environment where microbial contamination could be a concern, including dispenser systems, these considerations must be evaluated in the engineering design.

\section{Conclusions}

Bulk soap dispensers were shown to be highly contaminated, both by bacteria in the soap, and also 
by biofilm bacteria attached to the inner dispenser surfaces. The bacteria identified were consistent with those typically found in cosmetics/soap environments, as determined by both culture- and molecular-based identification analyses. The remediation effectiveness experiments demonstrated that, due to biofilm attached to the dispenser surfaces, even cleaning with highly concentrated disinfectants does not eliminate the bacterial populations that are adapted to live in the soap environment.

\section{Acknowledgement}

This project was funded by GOJO Industries, Inc.

\section{References}

Archibald L, Corl A, Shah B, Schulte M, Arduino M, Aguero S, Fisher D, Stechenberg B, Banerjee S, Jarvis W. 1997. Serratia marcescens outbreak associated with extrinsic contamination of $1 \%$ chlorxylenol soap. Infect Cont Hosp Ep 18:704-709.

Bannan E, Judge L. 1965. Bacteriological studies relating to handwashing. Am J Public Health Nations Health 55:915-922.

Beausoleil C. 1999. A guide for validation of neutralizer systems used in topical antimicrobial efficacy evaluations. In: Paulson DS, editor. Handbook of topical antimicrobials. New York (NY): Marcel Dekker, Inc. p. 365-376.

Brannan D, Dille J. 1990. Type of closure prevents microbial contamination of cosmetics during consumer use. Appl Environ Microb 56:1476-1479.

Buffet-Bataillon S, Rabier V, Bétrémieux P, Beuchée A, Bauer M, Pladys P, Le Gall E, Cormier M, JolivetGougeon A. 2009. Outbreak of Serratia marcescens in a neonatal intensive care unit: contaminated unmedicated liquid soap and risk factors. J Hosp Infect 72:17-22.

Burdon D, Whitby J. 1967. Contamination of hospital disinfectants with Pseudomonas species. Brit Med J 2:153-155.

Chattman M, Maxwell S, Gerba C. 2011. Occurrence of heterotrophic and coliform bacteria in liquid hand soaps from bulk refillable dispensers in public facilities. J Environ Health 73:26-29.

Donlan R, Costerton JW. 2002. Biofilms: survival mechanisms of clinically relevant microorganisms. Clin Microbiol Rev 15:167-193.

Garner J, Favero M. 1986. CDC guideline for handwashing and hospital environmental control. Infect Control $7: 231-243$.

Geis P. 2006. Preservation strategies. In: Geis P, editor. Cosmetic microbiology. Boca Raton (FL): Taylor \& Francis Group. p. 163-175.

Goeres DM. 2010. Understanding the importance of biofilm growth in hot tubs. In: Paulson D, editor. Applied biomedical microbiology. Boca Raton (FL): Taylor \& Francis Group. p. 133-148.

Graf W, Kersch D, Scherzer G. 1988. Microbial contamination of wall-mounted liquid soaps dispensers with singleuse bottles. [Translated from German]. Zbl Bakt Hyg B 186:166-179.
Hamilton M, Buckingham-Meyer K, Goeres D. 2009. Checking the validity of the harvesting and disaggregating steps in laboratory tests of surface disinfectants. J AOAC Int 92:1755-1762.

Hwang C, Wu W, Gentry T, Carley J, Corbin G, Carroll S, Watson D, Jardine P, Zhou J, Criddle C, et al. 2009. Bacterial community succession during in situ uranium bioremediation: spatial similarities along controlled flow paths. ISME J 3:47-64.

Kabara J, Brady M. 1983. Contamination of bar soaps under "in-use" conditions. J Environ Pathol Tox 5:1-14.

Krowka J, Bailey J. 2007. Establishing microbial quality of cosmetic products. CTFA microbiology guidelines 2007 [internet]. [Edition unknown]. Washington (DC): Cosmetic, Toiletry, and Fragrance Association; [cited 2011 Nov 3]. Available from: eservices.personalcarecouncil. org/site/vision_Bookstore_SplashPage2.htm

Mokhtari A, Jaykus L. 2009. Quantitative exposure model for the transmission of norovirus in retail food preparation. Int J Food Microbiol 133:38-47.

Morse L, Williams H, Grenn F, Eldridge E, Rotia J. 1967. Septicemia due to Klebsiella pneumonia originating from a hand-cream dispenser. N Engl J Med 277:472-473.

Peeters E, Nelis HJ, Coenye T. 2008. Evaluation of the efficacy of disinfection procedures against Burkholderia cenocepacia biofilms. J Hosp Infect 70:361-368.

Rabier V, Bataillon S, Jolivet-Gougeon A, Chapplain J-M, Beuchée A, Bétrémieux P. 2008. Hand washing soap as a source of neonatal Serratia marcescens outbreak. Acta Paediatr 97:1381-1385.

Sartor C, Jacomo V, Duvivier C, Tissot-Dupont H, Sambuc R, Drancourt M. 2000. Nosocomial Serratia marcescens infections associated with extrinsic contamination of a liquid nonmedicated soap. Infect Cont Hosp Ep 21:196199.

Smith K, Hunter I. 2008. Efficacy of common hospital biocides with biofilms of multi-drug resistant clinical isolates. J Med Microbiol 57:966-973.

Steinberg DC. 2006. Preservatives for cosmetics. 2nd ed. Carol Stream (IL): Allured Publishing Corporation. 137 pp.

Stewart P, McFeters G, Huang C. 2000. Biofilm control by antimicrobial agents. In: Bryers J, editor. Biofilms II: process analysis and applications. New York (NY): Wiley-Liss. p. 373-405.

Sutton S. 2006. Antimicrobial preservative efficacy and microbial content testing. In: Geis P, editor. Cosmetic microbiology. Boca Raton (FL): Taylor \& Francis Group. p. 112-139.

Ye Q, Roh Y, Carroll S, Blair B, Zhou J, Zhang C, Fields M. 2004. Alkaline anaerobic respiration: isolation and characterization of a novel alkaliphilic and metalreducing bacterium. Appl Environ Microb 70:5595-5602.

Zapka C, Campbell E, Maxwell S, Gerba C, Dolan M, Arbogast J, Macinga D. 2011. Bacterial hand contamination and transfer after use of contaminated bulk-soaprefillable dispensers. Appl Environ Microbiol 77:28982904. 